\title{
SOSIALISASI PENGENALAN DAN PELATIHAN PENGELOLAAN SISTEM INFORMASI AISYIYAH BAGI KADER AISYIYAH KOTA TASIKMALAYA
}

\author{
Ari Yuliati ${ }^{1}$ \\ ${ }^{1}$ Universitas Muhammadiyah Tasikmalaya \\ Email: aryuli@umtas.ac.id ${ }^{1}$
}

\begin{abstract}
ABSTRAK
Memasuki era Teknologi Informasi dan Komunikasi yang merambah hampir di semua lini kehidupan. Aktivitas manusia tidak dapat lepas dari sentuhan teknologi. 'Aisyiyah Kota Tasikmalaya sebagai sebuah organisasi masyarakat sipil, belum merespons kondisi masyarakat yang hampir semua berbasis teknologi. Salah satu upaya dalam pengelolaan pengetahuan (knowledge management) ini dengan diselenggarakan sosialisasi pengenalan dan pelatihan pengelolaan Sistem Informasi 'Aisyiyah (SIA) di wilayah Kota Tasikmalaya dengan harapan akan memperkuat kelembagaan 'Aisyiyah sehingga mampu memberikan kontribusi kepada umat dan bangsa menuju Indonesia berkemajuan. Program ini direncanakan bekerja sama dengan Lembaga Penelitian dan Pengembangan 'Aisyiyah (LPPA) Jawa Barat dan unsur serta jajaran Pimpinan Daerah 'Aisyiyah (PDA) di wilayah Kota Tasikmalaya.
\end{abstract}

Kata kunci : Knowledge management, SIA, PDA

\begin{abstract}
Entering the era of Information and Communication Technology that penetrated almost all lines of life. Human activity can not be separated from the touch of technology. 'Aisyiyah Kota Tasikmalaya as a civil society organization, has not responded to the condition of almost all society based on technology. One of the efforts in the management of this knowledge (knowledge management) will be held socialization and training management information system 'Aisyiyah (SIA) in the City of Tasikmalaya with the hope will strengthen institutional' Aisyiyah so as to contribute to the people and nation to Indonesia berkemajuan. The program is in collaboration with Aisyiyah (LPPA) Research Institute and Development of West Java and elements of Aisyiyah (PDA) Regional Leadership in Tasikmalaya City.
\end{abstract}

Keywords : Knowledge management, SIA, PDA 


\section{PENDAHULUAN}

Memasuki era teknologi informasi dan komunikasi yang semakin merambah hampir di semua lini kehidupan. Berdampak pada aktivitas manusia sehari-hari yang tidak dapat lepas dari sentuhan teknologi. Bahkan dapat dikatakan bahwa manusia sudah sangat tergantung pada teknologi informasi. 'Aisyiyah Kota Tasikmalaya sebagai sebuah organisasi masyarakat sipil, belum merespons kondisi masyarakat yang hampir semua berbasis teknologi. Informasi yang diperlukan oleh masyarakat masih berjalan secara manual dan sulit memperoleh berita atau agenda terbaru dari setiap kegiatan 'Aisyiyah kota Tasikmalaya.

Di sisi lain sumber daya manusia 'Aisyiyah kota Tasikmalaya sebagai organisasi yang berkhidmat dalam membangun peradaban baru yang ramah pada perempuan mempunyai harapan yang besar untuk mampu memperkuat kelembagaan "Aisyiyah. Sumber daya manusia untuk mendukung harapan ini memerlukan pembekalan pengetahuan di bidang teknologi informasi.

\section{BAHAN DAN METODE}

Berbagai pengetahuan dan pengalaman yang telah dikerjakan dan dikontribusikan oleh 'Aisyiyah kota Tasikmalaya dalam usianya yang ke-8 (delapan) tahun ini, belum secara maksimal didokumentasikan secara sistematis. Pengelolaan pengetahuan belum menjadi prioritas penting dalam menggerakkan organisasi meskipun pengetahuan dan pengalaman 'Aisyiyah kota Tasikmalaya memiliki nilai yang berharga untuk dibagikan secara internal maupun eksternal. Mengacu pada Rapat Kerja Nasional Pimpinan Pusat 'Aisyiyah bulan Mei 2016, tentang pengelolaan SIA yaitu website 'Aisyiyah di tingkat majelis/lembaga di setiap daerah, menjadi salah satu perhatian 'Aisyiyah dalam memperkuat organisasi dan sekaligus berkontribusi bagi kemajuan umat dan bangsa. Melalui program pengabdian masyarakat dengan sosialisasi pengenalan dan workshop sistem informasi 'Aisyiyah.

Pengabdian masyarakat ini berbentuk sosialisasi kepada majelis/ lembaga PRA, PCA, dan PDA Kota Tasikmalaya yang dilaksanakan pada hari minggu tanggal 18 Juni 2017 jam 08.00 wib, diikuti oleh 30 peserta dari tiap perwakilan PRA, PCA, dan PDA. Sosialisasi ini diawali dengan pemberian modul yang berisi petunjuk - petunjuk untuk mengelola sebuah WEB yang telah tersedia, kemudian peserta melakukan browsing lewat internet yang telah disediakan oleh panitia di notebook/laptop masing - masing. Adapun pada sosialisasi ini peserta dibantu langsung oleh panitia dalam mengelola WEB tersebut. Kegiatan sosialisasi ini selesai pada pukul 12.00 wib, diakhiri dengan pemberian bingkisan oleh panitia kepada peserta.

\section{HASIL}

Berdasarkan bahan dan metode tersebut, untuk menambah pengetahuan mengenai pengelolaan sistem informasi perlu adanya pelatihan terkait pengelolaan sistem informasi 'Aisyiyah. Penyuluhan ini akan bekerja sama dengan Lembaga Penelitian dan Pengembangan 'Aisyiyah (LPPA) Jawa Barat dan unsur serta jajaran Pimpinan Daerah 'Aisyiyah (PDA) di wilayah Kota Tasikmalaya.

Materi penyuluhan yang akan diberikan adalah terkait pengenalan dan pelatihan pengelolaan sistem informasi baik dari penggunaan username dan password sehingga dapat mengelola konten statis dan konten dinamis secara langsung. Konten statis antara 
lain terdiri dari informasi terkait dengan Profil, Struktur Organisasi, Tugas Pokok dan Fungsi, dan lain-lain. Sedangkan konten dinamis terdiri dari Berita, Agenda, Idea, Info Organisasi, Praktik Cerdas, Galeri, dan lain-lain. Sosialisasi mengenai SIA dengan memanfaatkan sumber daya manusia 'Aisyiyah sehingga memberi peluang kepada peserta untuk memberikan informasi agenda dan berita terbaru serta penyebaran informasi dapat dinikmati oleh masyarakat.

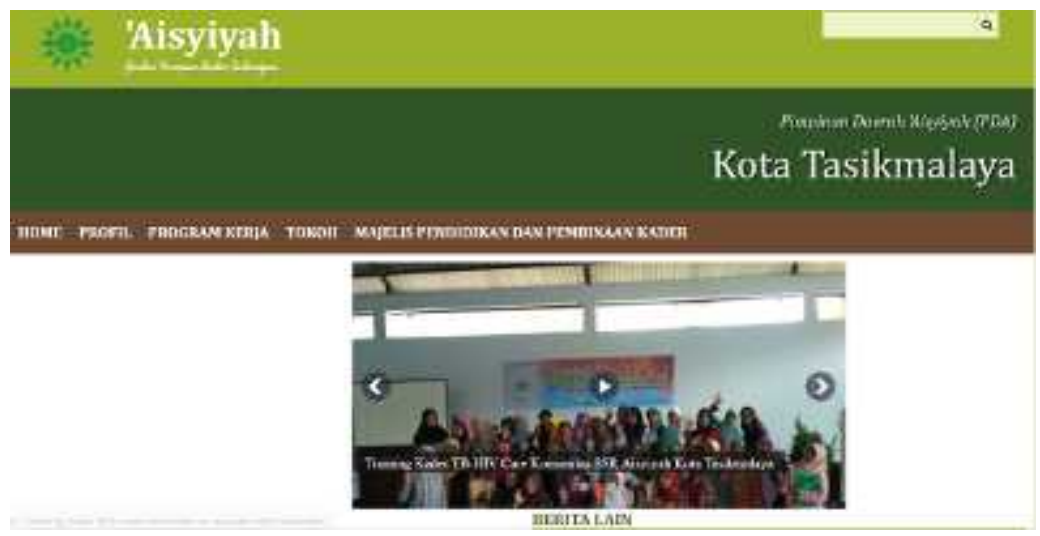

\section{Gambar 1. Tampilan Hasil Pengisian Konten Kegiatan Aisyiyah pada Website Aisyiyah Kota Tasikmalaya}

\section{PEMBAHASAN}

Adapun bahasan target yang ingin dicapai melalui penyuluhan ini adalah untuk menambah wawasan dan ilmu pengetahuan di bidang teknologi informasi bagi peserta di setiap unsur dan jajaran PRA, PCA, dan PDA Kota Tasikmalaya dalam hal pengelolaan WEB SIA. Selain itu dengan pemberian pelatihan mengenai pengelolaan SIA mengenai cara memasukkan gambar dan cara memasukkan file ini terjadilah komunikasi yang baik. Didalam website ini terdapat informasi tentang website SIA, berita, agenda yang berfungsi sebagai kalender kegiatan. Dengan adanya pelatihan diharapkan dapat memberikan nilai tambah bagi peserta, khususnya organisasi 'Aisyiyah Kota Tasikmalaya. Kemudian penyuluhan ini dapat pula dijadikan sebagai pemicu supaya Organisasi 'Aisyiyah dari daerah - daerah lain melakukan pergerakan memberikan informasi berita yang teraktual dan terpercaya mengenai pendidikan, ekonomi, sosial, politik, dan yang lainnya melalui WEB SIA ini.

Jika hasil pelatihan pengelolaan ini dapat dilaksanakan dengan baik, maka diharapkan pengetahuan dan pengalaman Organisasi 'Aisyiyah Kota Tasikmalaya dapat diaplikasikan secara maksimal oleh setiap unsur dan jajaran PRA, PCA, serta PDA Kota Tasikmalaya dalam WEB SIA yang bertujuan untuk mempererat tali silaturahmi, memperkuat organisasi dan sekaligus berkontribusi bagi kemuajuan umat dan bangsa. Serta pelatihan pengelolaan SIA ini dapat membidik rasa keingintahuan dan meningkatkan kapasitas sumber daya manusia 'Aisyiyah kota Tasikmalaya dalam kaitannya dengan ilmu pengetahuan, teknologi, dan kemudahan akses segala jenis informasi baik secara manual maupun digital.

\section{KESIMPULAN DAN SARAN}

Dari hasil penyuluhan tentang pelatihan pengelolaan sistem informasi ini, maka didapatkan suatu pengetahuan yang berkaitan dengan penggunaan username dan password dalam mengelola WEBSITE. Sehingga dengan kegiatan ini 'Aisyiyah Kota Tasikmalaya 
mempunyai sumber daya manusia yang unggul dapat mengelola konten statis dan konten dinamis secara langsung.

Untuk penyuluhan kedepannya diharapkan peserta dari PRA, PCA, dan PDA Kota Tasikmalaya supaya lebih antusias dan lebih siap terhadap materi yang akan diberikan supaya mendapatkan suatu informasi yang sangat berguna bagi kemajuan umat, bangsa, dan negara.

\section{UCAPAN TERIMA KASIH}

Kegiatan pengabdian pada masyarakat 2017 ini dapat terlaksana berkat dukungan dari berbagai pihak. Oleh karena itu kami menyampaikan terima kasih kepada 1) Rektor Universitas Muhammadiyah Tasikmalaya (Umtas) dan jajarannya, 2) LPPM Umtas dan staf , 3) Pimpinan PDA kota Tasikmalaya dan jajarannya, 4) Berbagai pihak yang tidak dapat kami sebutkan satu persatu yang telah membantu terlaksananya kegiatan pengabdian pada masyarakat ini.

\section{DAFTAR PUSTAKA}

Rapat Kerja Nasional Pimpinan Pusat 'Aisyiyah, Mei 2016, melalui : https://www.aisyiyah.or.id [27 Januari 2017].

Pengertian Sistem Informasi, 10 November 2013. "Pengertian Sistem Informasi". Melalui http://www.kompasiana.com [22 Februari 2017].

Lembaga Penelitian dan Pengembangan 'Aisyiyah (LPPA) dan Universitas

Muhammadiyah Malang (UMM). "Buku Panduan Pengelolaan Sistem Informasi

'Aisyiyah 2016". 


\section{LAMPIRAN}

Tabel 1. Jadwal Kegiatan periode 2017

\begin{tabular}{|c|c|c|c|c|c|c|c|c|c|}
\hline \multirow{2}{*}{ No. } & \multirow{2}{*}{ Aktixilas/kevialan } & \multicolumn{8}{|c|}{ Buka! } \\
\hline & & 1 & 2 & 3 & 4 & 5 & 6 & 7 & 8 \\
\hline 1. & Survering & & & & & & & & \\
\hline 2. & Analisis Situnsi & & & & & & & & \\
\hline 3. & Persiapan materi Pelatihan & & & & & & & & \\
\hline 4. & Pelaksandan P-lathan & & & & & & & & \\
\hline 5. & Pclapcran, Publikasi & & & & & & & & \\
\hline
\end{tabular}




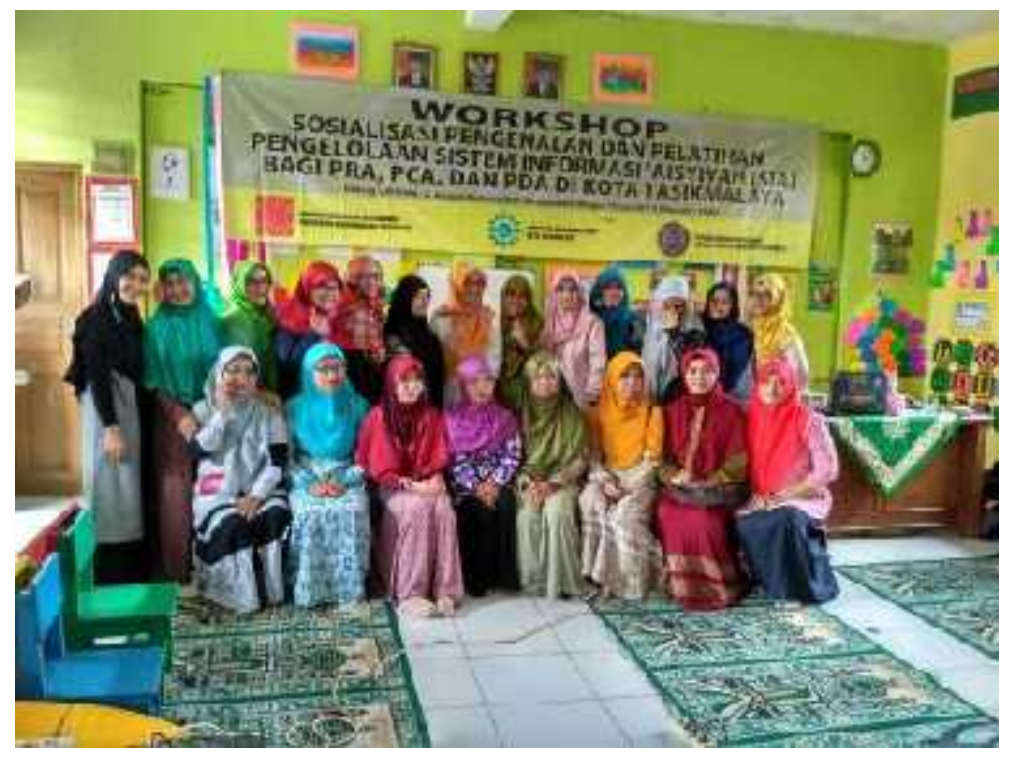

Gambar 1. Peserta Workshop SIA

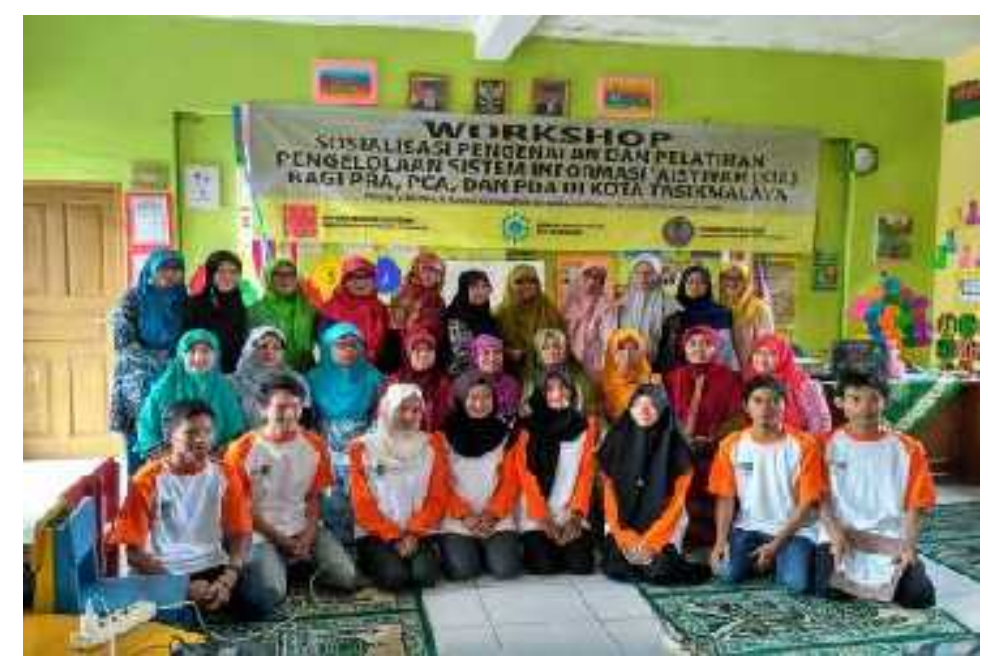

Gambar 2. Peserta dan Tim Panitya PPM Workshop SIA 


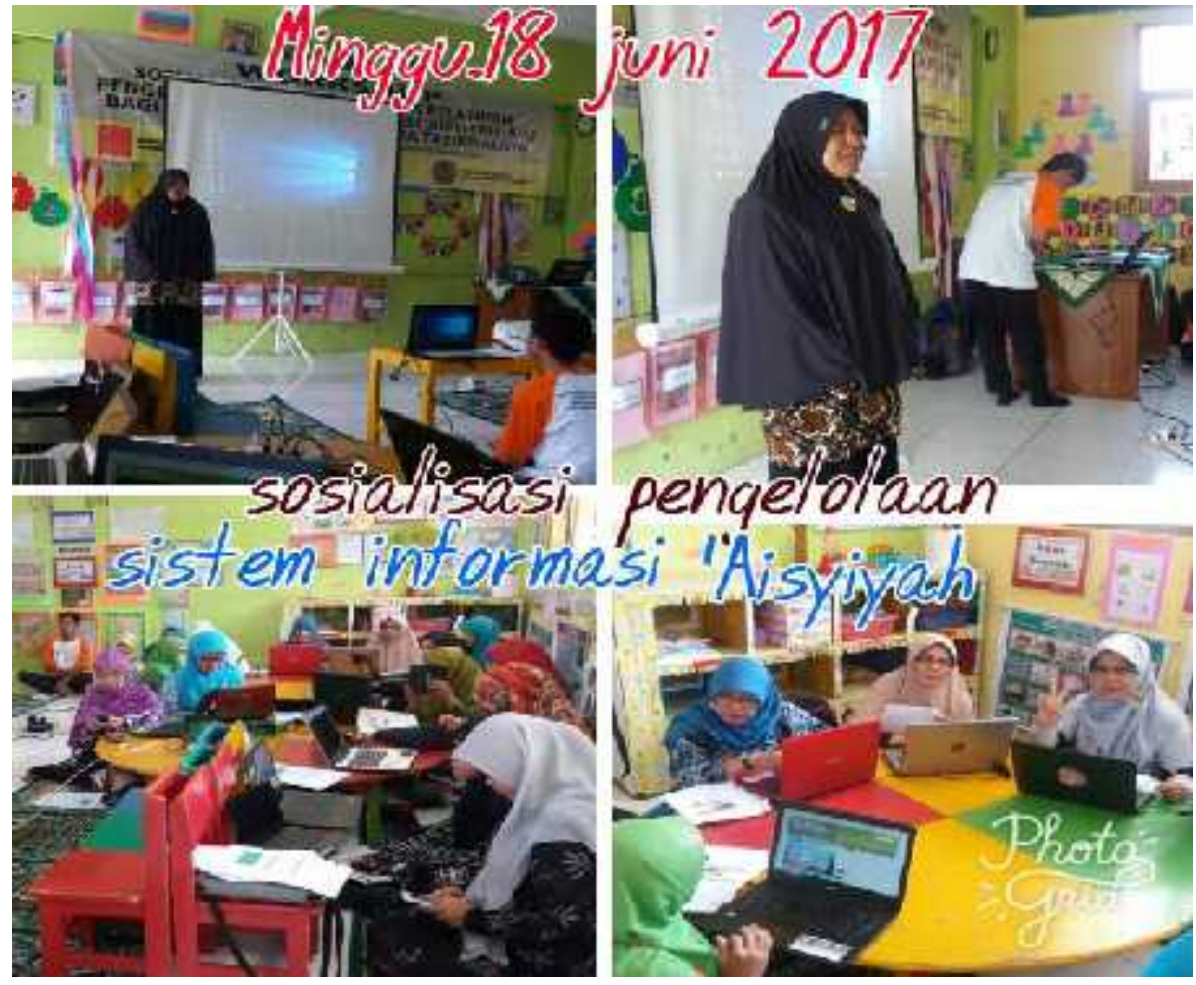

Gambar 3. Pembukaan oleh Ketua PDA Kota Tasikmalaya dan Pelaksanaan Kegiatan PPM Workshop SIA

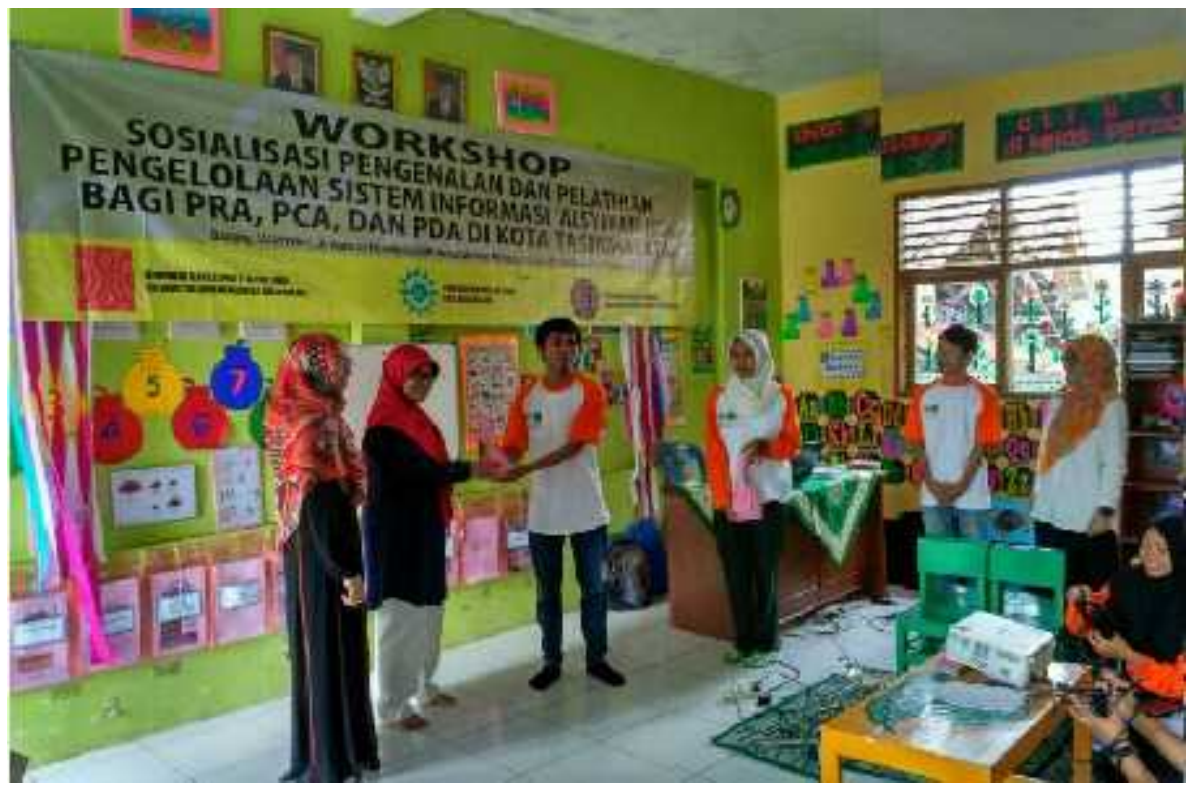

Gambar 4. Penyerahan cenderamata oleh Panitya kepada Perwakilan Peserta 